\title{
An Analysis of the Impact of Economic- Ecological Balance Mechanism Based on Non-Linear Partial Differential Equations on Land Financial Teaching Methods
}

\author{
Weiqing Wang1*, Lezhu Zhang1, Weikun Zhang' ${ }^{1}$ Ling Tao' ${ }^{1}$, Hanyuan Liang² \\ ${ }^{1}$ College of Economics and Management, South China Agricultural University, Guangzhou, China \\ ${ }^{2}$ Guangdong Ocean University Cunjin College, Zhanjiang, China \\ Email: *wwq432705@163.com
}

How to cite this paper: Wang, W.Q., Zhang, L.Z., Zhang, W.K., Tao, L. and Liang, H.Y. (2018) An Analysis of the Impact of Economic-Ecological Balance Mechanism Based on Non-Linear Partial Differential Equations on Land Financial Teaching Methods. Journal of Geoscience and Environment Protection, 6, 28-39. https://doi.org/10.4236/gep.2018.610002

Received: August 31, 2018

Accepted: October 14, 2018

Published: October 18, 2018

Copyright $(9) 2018$ by authors and Scientific Research Publishing Inc. This work is licensed under the Creative Commons Attribution International License (CC BY 4.0).

http://creativecommons.org/licenses/by/4.0/

\begin{abstract}
This paper clarifies the relationship between the flow paths of the corresponding ecological flows because of the ecological impact for land consolidation, using external energy methods to measure the external input of the project area or the output of ecological products. The application for nonlinear estimation of partial differential equations to land consolidation, the project ecological flow and system efficiency were quantitatively calculated. It shows that the conflict between fairness and efficiency is caused under conditions and levels of value and ecological compensation mechanism is built as a criterion for this ecological economics. Based on the years of use of the land improvement project, the time evolution of regional net ecological value, natural resource dependence, renewable resource dependence, ecological output ratio, ecological carrying capacity and ecological sustainability after the implementation of the project was assessed.
\end{abstract}

\section{Keywords}

Economic Ecological, Balance Mechanism, Non-Linear Partial Equation

\section{Introduction}

Land is the foundation upon which humanity depends, and it is the most precious natural resource for human beings. With population growth and rapid urbanization, land, especially cultivated land, needs to establish ecological red lines, just for food security ensured. The pressure on building a beautiful China is getting heavier and heavier. Land remediation is a policy tool used by many 
countries in the world to solve land use problems in the process of social-economic development, adjusting land use structure and layout, improving land relations and promoting rural development. In this macro context, land remediation will still play an important role in China's food security strategy, and it will have continuity and scale. With the advancement of new-style urbanization, land remediation will not only increase the amount of cultivated land, improve the quality of cultivated land, and ensure food security, but will also be combined with new urbanization and the coordinated development of urban and rural areas, and will gradually be transformed from natural engineering to comprehensive social engineering. It is an important way or method to solve the basic contradiction between the existing scattered management of rural areas and the trend of modern agriculture. Therefore, on the one hand, land remediation will be enriched during the era while increasing the effective arable land area and improving the quality of arable land. At the same time, land remediation has become one of the most significant land use methods in China at this stage (Alves \& Ribeiro, 2017) [1].

Capital is the basis for realizing value-added, is the driving force for expanding reproduction, and is an indispensable factor for promoting economic growth. Above all, improving the efficiency of financial capital allocation and optimizing resource allocation are the basis for the transformation and upgrading of economic structure and the maintenance of stable economic development. Analyzing the impact of financial ecology on economic growth from the perspective of capital allocation efficiency has important implications for improving capital allocation efficiency, increasing resource utilization, improving the function of financial markets and promoting economic development. The financial ecology not only includes economic factors closely related to financial operations, institutional changes, and other economic factors, but also includes environmental factors such as the political system, the legal environment, and the credit level of the entire society. The development and operation of financial entities have an important influence on the efficiency of capital allocation. The government behavior, economic foundation, credit environment and basic institutional construction mainly affect the efficiency of capital allocation by affecting the development of financial entities (Beaghton, Beaghton, \& Burt, 2016) [2]. This article uses Wurgler Jeffery's (2000) [3] capital allocation efficiency measurement method to construct an empirical model from the perspective of the subject of financial ecology to test the relationship between financial ecological indicators and capital allocation efficiency in the three coastal cities of Jiangsu Province, and to try to answer whether the financial ecology of three coastal cities in Jiangsu can improve capital allocation efficiency. To promote economic growth, the main contents include: Theoretical analysis of the impact of the development of financial ecology on economic growth, empirical examination of the relationship between financial ecology and capital allocation efficiency, and put forward corresponding countermeasures and suggestions. 


\section{Literature}

\subsection{Research Methods}

The construction behaviour of the land remediation project is a concentrated external stimulus to the farmland ecosystem and will have an impact on the ecological flow (material flow, energy flow, and information flow) in the project area. The conceptual model shown in Figure 1 shows this model. From the aspects of the flow and path of ecological flows, the changes in ecological flows that may be caused by land remediation projects are examined (Dey \& Ramachandra, 2017) [4]. The impact of land remediation projects on the input and output of farmland ecosystems' ecological flows is shown in Figure 2. It includes the natural resources, labour, environmental input, and ecological product output within the farmland ecosystem, and systematically analyzes land in terms of ecological flows and capital flows. After the rectification project was implemented, the one-time investment in land rectification activities and the changes in agricultural production inputs that triggered the renovation of project facilities during the operation period had a common impact on the ecosystem.

\subsection{Ecological Energy Analysis}

On the change of learning mode of cloud computing, scholars mainly from the two aspects of the transformation of collaborative learning and mobile learn to carry out specific research. The former is involved in a wide range of issues, the research issues are more in-depth, and the research content mainly includes the design of collaborative learning and practical application research. The impact of

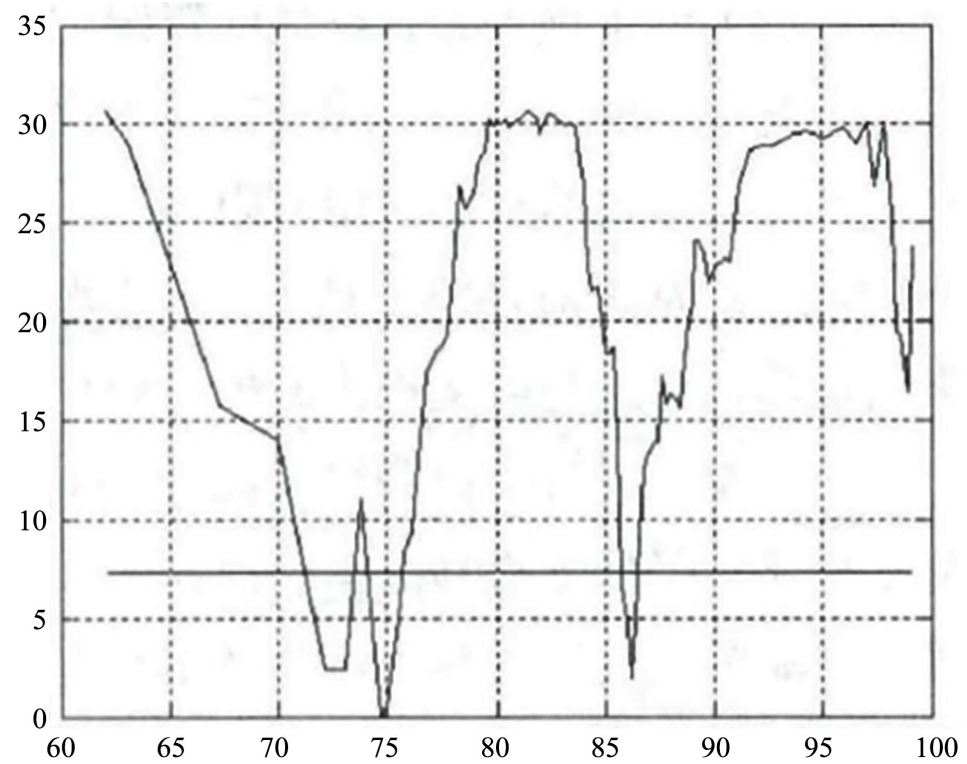

Figure 1. Double threshold effect 1. (Note: $\mathrm{x}$ axis for the external stimulus from land remediation behavior; $y$ axis for the changes of farmland ecological-system; Figure 1 reflect the ecological path or ecological flow the land remediation behavior bring, so it call for double threshold effect.) 


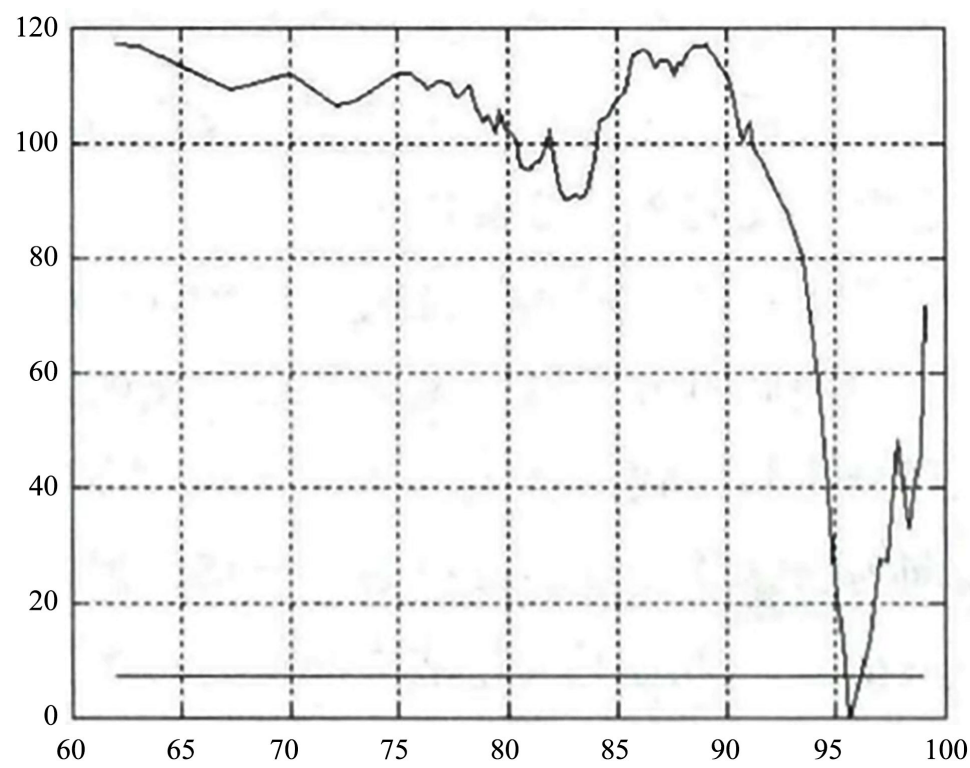

Figure 2. Double threshold effect 2. (Note: $\mathrm{x}$ axis for the stimulus of available energy and energy values; $y$ axis for the farmland ecosystem changes. Figure 2 reflects the various changes of the farmland ecosystem caused by previous stimulus of available energy and its values, so called in double threshold effect.)

cloud computing on mobile learning, the development of cloud computing based on the advantages of mobile learning, such as to make up for the lack of mobile learning mode; integration of resources; to create multiple independent support of virtual learning community; to reduce the requirements of mobile learning devices. Based on the above research results, construct the mobile learning model based on Hadoop, the students can be feedback problems in learning and learning resources for the needs of information for administrators and teachers, learning for students and teachers can also put forward some suggestions and requirements, supervise learning, constantly improve the system administrator according to the views of users (Dogan \& Seker, 2016) [5].

Available energy, also known as fire energy, is the energy in an ecosystem that, when the system reversibly changes from an arbitrary state to a state that is balanced with a given environment, the energy that can theoretically be infinitely converted to any other form of energy, The main fire energy parameters and representations as shown in formula (1), In the equation, $\eta_{E x}$ refers to the conversion rate (\%) of the stored value of fire, $E_{x i n}$ is the fire value $(\mathrm{J})$ that drives the entire process or system operation, and $E_{x o u t}$ refers to the energy value of the process output.

$$
\eta_{E x}=E x_{\text {in }} / E x_{\text {out }}
$$

According to the second law of thermodynamics, the definition of ecological fire density in ecosystems is:

$$
e x=R T \sum_{i=0}^{n}\left[c_{i} \ln \left(\frac{c_{i}}{c_{i}^{e q}}\right)+\left(c_{i}-c_{i}^{e q}\right)\right]
$$


In the formula, $R$ is the gas constant $\left(\mathrm{kJ} \mathrm{g}^{-1} \mathrm{~K}^{-1}\right)$; $\mathrm{T}$ is the absolute temperature $(\mathrm{K}) ; c_{i}$ and $c_{e}$ are the unit masses of the $\mathrm{i}$-th component of the ecosystem in the existing state and equilibrium state, respectively $\left(\mathrm{g} / \mathrm{m}^{3}\right) ; n$ is the $\mathrm{n}$ components present in the system.

Compared with the contribution of unit mass in the system components to ecological fire, the contribution of pressure and temperature is very small. Therefore, for the practical application, the calculation process is simplified, and the impact of pressure and temperature on the final result is ignored. The energy index between the main energy input and output in the ecosystem is expressed as:

$$
e X=\phi \sum_{i=0}^{n} \beta_{i} c_{i}
$$

In the formula, $\varphi$ refers to the coefficient affecting the system balance; $\beta_{\mathrm{i}}$ refers to the weight of each component $i$ in the ecosystem, which can be calculated according to the information of the elements within the system or the content of the components at a certain level, and obtained through experimental methods.

The ecological impact assessment index refers to the previous analysis of available energy and energy values, reflecting the ecological impacts of various aspects of the farmland ecosystem. The main evaluation indicators include net ecological value, natural resource dependence, renewable natural resource dependence, and ecology. The comparison of land remediation activities and the flow of funds generated in agricultural production activities with ecological flows provide data support for the economic benefits of land remediation planning. Through the quantitative calculation of these indicators, the impact of land remediation activities in the study area on the ecological environment within a certain space and time range can be evaluated. The net ecological value is calculated as follows:

$$
N E V=Y-I
$$

The net ecological value ( $N E V$ ) is obtained by comparing the difference between ecological output $(Y)$ and ecological input $(I)$, which reflects the total impact of land remediation on the stability of the farmland ecosystem. The NEV value is positive, indicating that the land remediation is on farmland. Ecosystems have a surplus of ecological benefits, but on the contrary have a negative impact on ecological benefits. Then the natural resource dependence is calculated as follows:

$$
N D=\frac{N}{I}=\frac{A N+O N}{A N+A P+O N+O P}
$$

Natural resource dependence $(N D)$ is the ratio of the total of input natural resources $(N)$ to total input $(I)$, which reflects the degree of dependence of farmland ecosystems on natural resource input after the implementation of land remediation. 


\section{Result Analysis}

\subsection{Emerge Conversion Rate}

The degree of dependence on natural resources and renewable resources decreases with time, but the change is small, still between $1 \%$ and $2 \%$. The proportion of available renewable energy inputs can be used as a percentage of available energy for ecological input. $69 \%$, therefore, the input of one-time renewable resources has little effect on the farmland ecosystem in the study area; the ecological carrying capacity and ecological sustainability are directly proportional to the time change, with a small change; net ecological value and ecology the output rate changes greatly with time. One-time non-renewable purchase of resources has a great impact on the ecosystem. The farmland ecosystem needs to recover for a certain period of time before it can recover to the natural balance of the system, as for Table 1. The results of the emerge analysis (seeing Table 1) show that the farmland ecosystem can be relatively balanced after being affected by the concentration of land consolidation activities for $4 \mathrm{a}$, and its ecological benefits turn from negative to positive. When the ecological benefits are negative, the maximum value is $21.02 \mathrm{EJ}$, about 3000 times of the available energy value; The change trend of the ecological efficiency measured by the energy value method is similar to the available energy value method, but the impact of land remediation on the regional farmland ecosystem is significantly different from that of the available energy value method (Golden et al., 2016) [6]. Changes in other indicators calculated by the value method were all slowed down after the 15th year of implementation of the land remediation project. Emerge is actually expressed as an energy memory that represents the sum of all energy that passes through the primary and secondary production of the system, rather than the energy contained in the actual system. All the energy values are put into the farmland ecosystem and then input. Among the food crops that are produced,

Table 1. The ecological flow index change.

\begin{tabular}{|c|c|c|c|c|c|c|}
\hline \multirow{2}{*}{ Eco-flow } & \multicolumn{3}{|c|}{$\mathrm{Tj}$} & \multicolumn{3}{|c|}{ Pej } \\
\hline & \multicolumn{6}{|c|}{ Model I Model II Model III Model I Model II Model III } \\
\hline Annual renewable natural resource input & 33.20 & 584 & 0.80 & 9.76 & 282 & 0.74 \\
\hline Annual purchase renewable resource input & 1940 & 11,100 & 68.30 & 606 & 6230 & 65.20 \\
\hline $\begin{array}{c}\text { Annual purchase non-renewable resource } \\
\text { input }\end{array}$ & -1590 & 103 & -24.80 & -230 & 5260 & 1.60 \\
\hline One-off renewable natural resource input & 1.67 & 4.79 & 0.13 & 1.56 & 3.94 & 0.04 \\
\hline $\begin{array}{c}\text { One-off purchase non-renewable resource } \\
\text { input }\end{array}$ & 8.04 & 5.42 & 1.30 & 7.04 & 4.54 & 1.17 \\
\hline annual ecological output & 21.17 & 106.41 & 63.90 & 67.30 & 188.97 & 66.96 \\
\hline One-off ecological output & 11.43 & 17.48 & 77.00 & 13.20 & 21.09 & 85.77 \\
\hline Ecological indicators & 1.85 & 6.09 & 0.83 & 5.10 & 8.96 & 0.78 \\
\hline
\end{tabular}


the energy value only records the sources and whereabouts of natural and social ecological flows and financial flows, and has nothing to do with the agricultural production process and input methods.

In the fourth year after the implementation of the project, the ecological benefits turned positive, the natural resource dependence was $4.79 \%$, and the renewable resource dependency was $5.42 \%$ (seeing Table 1). This shows that the self-renewal capacity of the farmland ecosystem in the study area is weak; the power is 17.48 , which is higher than the available energy calculation result. The system purchases resources and non-renewable natural resources above the renewable energy resources, reflecting that the system input is still dominated by non-renewable purchasing resources. In the 15th year after the implementation of the project, the system's energy output rate was $188.97 \%$, indicating that the system will attract more and more energy input after a relatively balanced period of time. In view of the increase in ecological carrying capacity, the natural resources of the system will increase (shown in Table 1). The reduction of renewable resource dependencies will cause an increase in the annual purchase of resource inputs, such as pesticides, fertilizers, and agricultural films, which may cause a new round of changes in system dynamics (Gómezdans, Lewis, \& Disney, 2016) [7]. In the 29th year after the implementation of the project, that is, when the eco-efficiency in the available energy method turns to a positive value, the ecosystem energy output rate of the system is as high as $218.76 \%$, but the increase rate is obviously slowed down. At the same time, natural resource dependence and renewable natural resources are dependent on Degree and ecological carrying capacity tends to be stable.

\subsection{Capital Flow Efficiency}

In the impact of land remediation projects on the input and output of farmland ecosystem capital flows, the economic benefits of land remediation projects can be seen as negative from an ecosystem perspective, and the net ecological value trend of capital flows started in the third year after project implementation. At the same time, the ecological output rate and ecological carrying capacity also tend to be stable, and the ecological sustainability level is almost unchanged after the net ecological value becomes positive, still between $0.7 \%$ and $0.9 \%$; the capital investment in land remediation projects cannot be exchanged for the same output (seeing Figure 3). At the same time, it also requires a certain amount of investment in agricultural resources each year. However, taking into account the ecological and social benefits that the project implements at the same time, the overall benefit is the level at which the benefits can be greater than the investment. The investment payback period in the economic benefit calculation of this project is $3 \mathrm{a}$. The research results can confirm that the capital flows back to the relative equilibrium level after the investment payback period, in which the annual agricultural production and operation funds accounted for $78.35 \%$ of the total capital investment, and therefore only in the land. The initial impact of the 


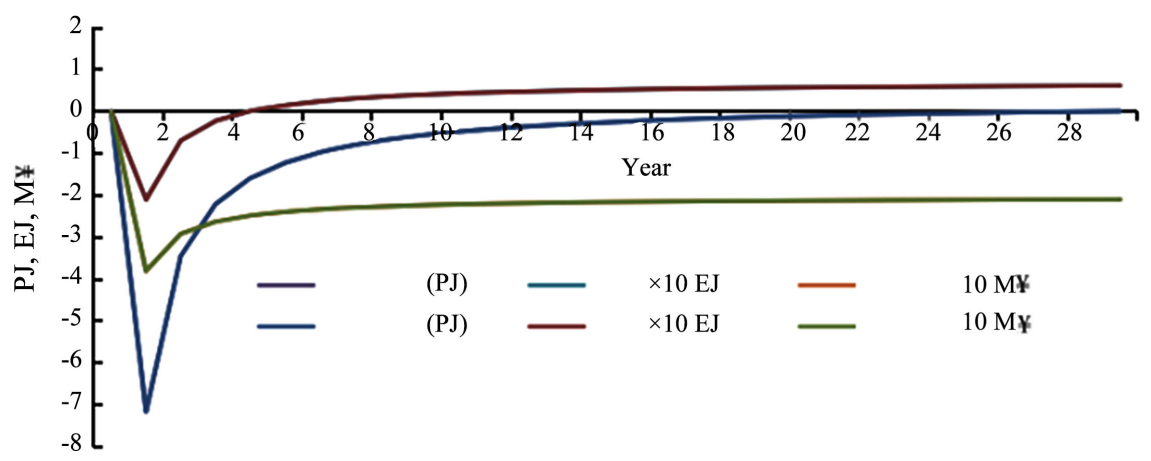

Figure 3. Net ecological benefits.

rectification project on the flow of farmland ecosystems is more obvious (Groh, Kohr, \& Louis, 2016) [8].

\section{Net Ecological Value}

\subsection{Natural Resource Dependence}

The land remediation project has the most obvious effect on the net ecological value of farmland ecosystems. It can reflect the ecological benefits and its change process through the net ecological value. Using the available energy or energy method, the ecological impact of the land remediation project in the study area has shown a process from the steep increase in the negative ecological value to the index change in the initial stage of the project to a gradual and positive transition, indicating the land in the region. The impact of remediation on ecosystems has long-term and dynamic changes. There will be differences in the impact of different land remediation project implementation. This study analyzes the general trend of impact through the net ecological value index and predicts the impact time of the study area and the characteristics of various changes in the ecosystem (James, Hart, Banay, \& Laden, 2016) [9].

The degree of dependence on natural resources in the study area has been decreasing since the implementation of the project, and the base value of the initial stage of the project implementation is also very small, indicating the dependence of the research area on purchasing resources, comparison of natural resource investment and purchase of resources, The available energy and energy input for purchasing resource input are approximately 112.7 times and 30.6 times for annual natural resource input, respectively; the available energy and energy value for one-time purchase of resource input are approximately 57.2 times that of one-time natural resource input. Among the annual purchases of resources, pesticides, fertilizers and agricultural films have a higher proportion of possible energy use and energy value. Among the possible energy use and energy input for one-time purchase of resources, sand, gravel, and steel account for a relatively large proportion. The purchase of resources has a long-term impact on the ecological environment, but it is a common resource in land remediation and agricultural production. Therefore, the input of such resources should be mini- 
mized. Updatable resources are indispensable resources in the system, which can not only maintain system stability, but also increase the sustainability of the system. The renewable resource dependency of the study area is slightly higher than that of natural resources. Among them, the tree input available energy accounts for $6.67 \%$ of the total resource input.

\subsection{Ecological Sustainability}

There are fewer renewable resources input in the ecosystem, and there are more non-renewable resources. The non-renewable resources in the input account for more than $90 \%$ of the total input resources, which seriously affects the ability of the farmland ecosystem to update and recover. Therefore, in the land remediation activities, consideration should be given to multi-input renewable resources, such as increasing tree planting and planting of vegetation, which will not only improve the system's renewability, but also increase more ecological output and effectively improve the ecosystem of the system. The change rate of the ecological output rate in the study area varies from low to high, and its growth rate gradually decreases. After the relatively stable period (4a) and natural stability period (29a), the corresponding output rate will be higher than 100 respectively. At this time, the farmland ecosystem began to produce positive ecological benefits.

The energy-calculated result is about 2 - 8 times that of the available energy. It can be seen that the system's effective output rate still needs to be improved. In the later land remediation project planning, some of the purchased resources can be replaced with strong updating ability and can be effectively improved. The ecological carrying capacity gradually increased after the implementation of the land remediation project, but the extent of change was small, indicating that the carrying capacity of the farmland ecosystem needs to be gradually increased to maintain stability, which will have an impact on the self-recovery capacity of the system, and will also affect some ecological benefits. Generate offsets, etc. The increase in non-renewable resources and natural resources purchased by the system will affect the ecological carrying capacity of the system (Lejeune, Boudaoud, Potier-Ferry, Charpentier, \& Zahrouni, 2013) [10]. The ecological sustainability of the system has been increasing year by year after implementation of the remediation project. The base and the extent of change are relatively small. The ecological sustainability of the system is relatively weak. It is necessary to increase the net ecological benefits and increase the ecological output ratio in the agricultural production process. Since higher ecological output rates will attract annual resources, it is still necessary to reduce some of the purchase of resources, especially pesticides and chemical fertilizers, in agricultural production.

\subsection{Eco-Economic Principles}

Ecological compensation is to restore and rebuild ecosystems, so that the eco- 
system has good material and energy cycle functions and self-purification, so that the ecosystem maintains a high energy conversion rate, material accumulation rate, and maximum self-purification capability. This is the ecological benefit; the economic benefits require improving the utilization of environmental resources while maintaining a good ecological environment so as to maximize input and output. Therefore, in the ecological compensation, we must use the largest input in exchange for maximum ecological benefits, use ecological benefits to better serve economic benefits, and good economic benefits can provide economic foundations for ecological compensation, which is consistent with the requirements of sustainable development. Therefore, we should judge the ecological economic principles of the ecological compensation mechanism should be a combination of ecological benefits and economic benefits (Ruggieri \& Speciale, 2017) [11].

\section{Conclusions}

When considering the value objectives of rights arrangements in environmental resources law, traditional jurisprudence is often measured by standards of fairness and justice. But the standards of fairness and justice are based on subjective value judgments. Even if objective standards are involved, the measurement of benefits is often limited to empirical observations, but lacks theoretical examples. In fact, fairness and justice are by no means contrary to utilitarianism. It is only the value objective of classical natural law. Aristotle distinguished the justness of exchange and the justice of distribution. The conflict between fairness and efficiency is caused by differences in their respective connotations under different conditions and different levels of value. They are entirely possible to unite at a certain value end point. The ecological compensation mechanism should use efficiency as a criterion for its ecological economics because it allows ecological destroyers to compensate the ecological builders economically (Thomas \& Martin, 2004) [12]. If the beneficiaries receive more compensation than the destroyers have done on the ecosystem, the result is an overall social with the increase in welfare; a Pareto Improvement has been achieved, which is a step toward the ideal kingdom of distributive justice while not violating efficiency. This also shows that in the field of modern environmental resources law, the principle of fairness has its own unique standards and interpretations. The implementation of ecological compensation system will inevitably involve the distribution of benefits and resources.

And regulation, this necessarily has damage to one side. The applicability of Pareto equilibrium and Pareto improvement to the real legal world is not as large as it seems. Because the object of legal adjustment is a complex social relationship, each law is beneficial to some people, but it must be less favorable or even harmful to others. So there is the Kaldor-Hicks reform, which means that in the reform, the total benefit is greater than the total amount of damage, so that the beneficiary can compensate the injured, so that it is not damaged or the 
damage is minimal. Strictly speaking, the Kardo-Hicks reform is a transformation of the Pareto reforms to the Pareto reforms through sweeping and compensation (Visser, Ibelings, Bormans, \& Huisman, 2016) [13]. Carldo stated: "Any potential change will be subject to the following quiz: Ask all those who have been adversely affected by the results of the innovation and think that the inconvenience caused by the innovation will have as little monetary compensation as possible. Similarly, all causes must be asked. The person who receives the innovation will estimate how much the highest willingness will give up without giving up the benefits already obtained. As long as the sum of the latter is greater than the sum of the former, it can be concluded that this is a socially desirable innovation." This means that if a law is Institutional arrangements increase the welfare of some people and at the same time reduce the welfare of others. Then, as long as the added benefits outweigh the reduced benefits, the law can be considered as adding value to the overall social welfare. Therefore, this law is consistent with efficiency. In other words, as long as legal gain holders can compensate the injured, the final legal arrangement is efficient.

\section{Conflicts of Interest}

The authors declare no conflicts of interest regarding the publication of this paper.

\section{References}

[1] Alves, M. and Ribeiro, P. (2017) Non-Linear Modes of Vibration of Timoshenko Nanobeams under Electrostatic Actuation. International Journal of Mechanical Sciences, 130, 188-202. https://doi.org/10.1016/j.ijmecsci.2017.06.003

[2] Beaghton, A., Beaghton, P.J. and Burt, A. (2016) Gene Drive through a Landscape: Reaction-Diffusion Models of Population Suppression and Elimination by a Sex Ratio Distorter. Theoretical Population Biology, 108, 51-69. https://doi.org/10.1016/j.tpb.2015.11.005

[3] Jeffery, W. (2000) Financial Market and the Allocation of Capital. Journal of Financial Economics, 58,187-214

[4] Dey, T. and Ramachandra, L.S. (2017) Non-Linear Vibration Analysis of Laminated Composite Circular Cylindrical Shells. Composite Structures, 163, 89-100. https://doi.org/10.1016/j.compstruct.2016.12.018

[5] Dogan, E. and Seker, F. (2016) Determinants of $\mathrm{CO}_{2}$, Emissions in the European Union: The Role of Renewable and Non-Renewable Energy. Renewable Energy, 94, 429-439. https://doi.org/10.1016/j.renene.2016.03.078

[6] Golden, H.E., Sander, H.A., Lane, C.R., Zhao, C., Price, K., D’Amico, E., et al. (2016) Relative Effects of Geographically Isolated Wetlands on Streamflow: A Watershed-Scale Analysis. Ecohydrology, 9, 21-38. https://doi.org/10.1002/eco.1608

[7] Gómezdans, J., Lewis, P. and Disney, M. (2016) Efficient Emulation of Radiative Transfer Codes Using Gaussian Processes and Application to Land Surface Parameter Inferences. Remote Sensing, 8, 119. https://doi.org/10.3390/rs8020119

[8] Groh, A., Kohr, H. and Louis, A.K. (2016) Numerical Rate Function Determination in Partial Differential Equations Modeling Cell Population Dynamics. Journal of 
Mathematical Biology, 74, 1-33.

[9] James, P., Hart, J.E., Banay, R.F. and Laden, F. (2016) Exposure to Greenness and Mortality in a Nationwide Prospective Cohort Study of Women. Environmental Health Perspectives, 124, 1344-1352. https://doi.org/10.1289/ehp.1510363

[10] Lejeune, A., Boudaoud, H., Potier-Ferry, M., Charpentier, I. and Zahrouni, H. (2013) Automatic Solver for Non-Linear Partial Differential Equations with Implicit Local Laws: Application to Unilateral Contact. International Journal for Numerical Methods in Engineering, 94, 850-867. https://doi.org/10.1002/nme.4483

[11] Ruggieri, M. and Speciale, M.P. (2017) Construction of Balance Laws of First Order Quasilinear Systems of Partial Differential Equations. International Conference of Numerical Analysis \& Applied Mathematics, 1863.

https://doi.org/10.1063/1.4992676

[12] Hélie, T. and Hasler, M. (2004) Volterra Series for Solving Weakly Non-Linear Partial Differential Equations: Application to a Dissipative Burgers' Equation. International Journal of Control, 77, 1071-1082. https://doi.org/10.1080/002071704200024365

[13] Visser, P.M., Ibelings, B.W., Bormans, M. and Huisman, J. (2016) Artificial Mixing to Control Cyanobacterial Blooms: A Review. Aquatic Ecology, 50, 423-441. https://doi.org/10.1007/s10452-015-9537-0 